\title{
INGLÊS COMO LÍNGUA FRANCA: ENSINO-APRENDIZAGEM E FORMAÇÃO DE PROFESSORES
}

\author{
English as a Lingua Franca: teaching and learning and teacher education
}

\author{
Telma GIMENEZ; Luciana Cabrini Simões CALVO; Michele Salles EL KADRI \\ (organizadoras)
}

\author{
Resenhado por: Alessandra Augusta Pereira da SILVA, UNESPAR /FECILCAM ${ }^{1}$ \\ Célia Carrião JASNIEVSK, UNESPAR/FECILCAM ${ }^{2}$
}

\begin{abstract}
RESUMO: Esta resenha visa apresentar a obra Inglês como Língua Franca: ensinoaprendizagem e formação de professores (English as a Lingua Franca: teaching and learning and teacher education), organizada pelas pesquisadoras Telma Gimenez, Luciana Cabrini Simões e Michele Salles El Kadri ao tratar do novo estatuto em que a língua inglesa se encontra na sociedade atual e como essa mudança desafia direta e indiretamente os agentes envolvidos nos processos de formação docente e escolar, antes limitados a poucos linguístas aplicados. A obra reúne autores nacionais e internacionais que se lançam no encalço da polêmica redefinição do estatuto da língua inglesa no mundo e convida o leitor, professor, pesquisador e linguista aplicado, a refletir sobre sua própria concepção do que seja a língua inglesa no mundo e como isso implica em sua maneira de aprender e ensinar.

PALAVRAS-CHAVE: Inglês como Língua Franca; Formação de Professores; Ensino; Aprendizagem.
\end{abstract}

ABSTRACT: This review aims to present the book 'English as a Lingua Franca: teaching and learning and teacher education', organized by the researchers Telma Gimenez, Luciana Cabrini Simões and Michele Salles El Kadri as they deal with the new status of the English language in currently society and how this change challenges directly and indirectly the agents involved in the processes of teacher education and schooling, before limited to a few applied linguists. The work brings together national and international authors who dare to pursuit the controversial redefinition of the status of English in the world and invites the reader, teacher, researcher and applied linguists, to reflect on their own conception of what the English language is in the world and how this implies a way to learn and teach.

KEY-WORDS: English as a Lingua Franca; Teacher Education; Teaching; Learning.

\footnotetext{
${ }^{1}$ Docente da área de Língua Inglesa do departamento de Letras da UNESPAR/FECILCAM. Doutoranda em Estudos da Linguagem - UEL.

${ }^{2}$ Docente de língua inglesa do Cenro de Línguas da UNESPAR/FECILCAM. Mestranda em Estudos da Linguagem - UEL.
} 
A obra Inglês como Língua Franca: ensino-aprendizagem e formação de professores, organizada pelas pesquisadoras Telma Gimenez, Luciana Cabrini Simões e Michele Salles El Kadri, é uma das poucas obras brasileiras que ineditamente reúne diversos pesquisadores nacionais e estrangeiros para discutir o estatuto atual da língua inglesa no mundo e desafia o leitor a refletir sobre o significado dessa língua para vários povos, especificamente quando se trata do lócus de ensino-aprendizagem e formação de professores, sendo esse lócus privilegiado como público alvo do livro, bem como pesquisadores da área de Linguística Aplicada, gestores de políticas para o ensino de língua inglesa e áreas afins. É no encalço da polêmica redefinição do estatuto da língua inglesa no mundo, como uma língua franca, que a obra se situa, incluindo discussões trazidas a partir de conceitos dessa língua como World English, International English ou English as a língua franca.

No âmbito internacional alguns dos pesquisadores envolvidos na discussão dessa obra englobam Kachru (1985), Crystal (1997), Seidlhofer (2004) Canagarajah (2006), Graddol (2006), Kirkpatric (2007) e muitos outros. No Brasil as pesquisas ainda são poucas, mas iniciativas, tais como tomadas por Leffa (2002), Gimenez (2006, 2009), Siqueira (2008), Jordão (2009), Becker (2009), dentre outros, evidenciam que as pesquisas nessa perspectiva estão em ascensão.

Ela apresenta primordialmente duas principais contribuições para a área de Linguística Aplicada e formação de professores, a primeira para os professores formadores em sua reflexão e posicionamento frente aos discursos cristalizados pela sociedade, entre eles, a importância do inglês no mundo globalizado, que, não raras exceções, serve equivocadamente como argumento para a propagação do inglês como mercadoria e, ao mesmo tempo, como objeto de exclusão. Uma segunda grande contribuição desta obra está na superação dos limites do ambiente acadêmico, podendo contribuir também para os professores que atuam em escolas da educação básica e de idiomas.

A compilação dos dez artigos e uma entrevista culminou na convergência de que o inglês é uma língua globalizada e falada por muitos mais falantes do círculo em expansão do que do círculo interno (Kachru, 1985) e de que esse estatuto da língua traz implicações diretas para o ensino-aprendizagem da língua inglesa, quer queiramos ou não. Isto faz com que o papel do professor seja urgentemente repensado.

Ao abordar o estatuto da língua inglesa no Brasil, o primeiro capítulo, sob a autoria de Luciana Cabrini Simões Calvo e Michele Salles El Kadri, teve como objetivo mapear estudos brasileiros sobre Inglês como Língua Franca (ILF) para que um inventário 
de elementos constitutivos dessas pesquisas fosse elaborado; focando avanços e lacunas nas pesquisas, objetos de estudo. Os avanços evidenciados foram o aumento de pessoas discutindo o fenômeno, revelando uma preocupação cada vez maior com o contexto de ensino-aprendizagem da língua e da formação inicial, dentre outros. O grande desafio deixado pelo artigo é a necessidade de haver uma transposição da discussão sobre o novo estatuto da LI para as políticas públicas educacionais.

O segundo capítulo é delineado unicamente pelos conceitos sobre a língua inglesa no mundo. Produzido por Kanavillil Rajagopalan, o texto adota a terminologia World English (WE) - inglês global - definindo-o pelo que ele não é, ao problematizar a não familiaridade do termo na sociedade de modo geral, exceto por um número ínfimo de linguistas aplicados. O autor aborda a necessidade de repensar a definição de língua já que o WE implica em novas maneiras de pensar e, eventualmente em uma necessária revisão nos conceitos de língua, já que ele representa um fenômeno inédito na história da humanidade cujo falante nativo não é mais colocado como o modelo a ser seguido.

O terceiro capítulo aborda como tema central o ensino de língua inglesa em contextos gerais. Nessa temática, Margaret Pederson, professora em contextos, tanto de inglês como língua estrangeira como segunda língua, alerta para a necessidade de se considerar a cultura e a identidade dos falantes de cada lugar, sem marginalizar, por exemplo, os falantes nativos. Ela ainda traz à tona a questão da inteligibilidade e questiona quem decide o que é inteligível e em quais contextos. No entanto, ela acredita que uma inteligibilidade mútua com base no sotaque do nativo deveria ser enfatizada entre alunos e professores.

Sávio Siqueira, no capítulo quatro, estende a visão apresentada por Pederson, ao propor uma pedagogia intercultural crítica com foco político, considerando o ensino de língua inglesa como um idioma desterritorializado. O autor explora majoritariamente duas terminologias utilizadas para falar desse fenômeno: inglês como língua internacional (ILI) e inglês como língua franca (LF) que, segundo o autor, tendem a confluir para o mesmo lugar. Para Siqueira, a grande questão não é se temos que ensinar cultura, mas como ensiná-la. Ele ainda conclui que uma relação entre a área de ensino-aprendizagem de ILF com a de comunicação intercultural se faz necessária e implicaria na abertura de espaço para os marginalizados voltarem para a sala de aula e possibilidade de tomada de consciência sobre a diversidade e democratização.

Já o quinto capítulo, produzido por Graça Juliana Mello Monaris Costa e Telma Gimenez, traz como pano de fundo o fenômeno do ensino de inglês em uma aldeia do 
interior do Paraná para problematizar os significados da língua inglesa no Brasil a partir de duas posições principais: inglês como uma língua do imperialismo ou uma língua que pode possibilitar a transformação. Ao refletir sobre esse fato, em uma aldeia cuja língua inglesa é sua terceira língua e apenas recém-iniciada na escola, as autoras evidenciam a influência da cultura "pop" americana em um contexto que, a princípio, pressupostamente, seria uma das mais distantes dessa cultura. Assim, o grande desafio posto à professora local era a conciliação da manutenção da identidade indígena com o aprendizado de uma língua que possuía um estatuto tão complexo na contemporaneidade, como é o caso da língua inglesa.

Seguindo ainda nesta temática, no sexto capítulo, Patrícia Linck Berto, a partir de um estudo de caso, discute o ensino de inglês sob o novo estatuto de língua global e como este fato tem sido tratado no contexto educacional brasileiro. A autora investiga o posicionamento de 24 alunos da graduação, atuantes como professores de inglês. Tomando como base os objetivos do ensino de língua estrangeira propostos pelos Parâmetros Curriculares Nacionais, ela vê a necessidade de os professores reavaliarem seus conceitos ao pensar em outras variedades, regras e sotaques, baseando suas aulas de inglês em propósitos internacionais. A autora afirma que esta questão não tem sido tratada de forma adequada nos cursos de formação de professores de inglês. No entanto, os resultados da pesquisa são otimistas, pois apontam que a maioria dos professores apoia ou, pelo menos, está ciente da mudança do papel do inglês no mundo e a influência que esta mudança acarreta no ensino.

Somando-se a temática apontada pelo capítulo anterior, Michele Salles El Kadri, sétimo artigo, analisa a atitude dos professores formadores em cursos de Letras-inglês com relação ao estatuto do inglês como língua franca num curso de formação inicial. A autora procura identificar, por meio de questionário aberto, primeiramente, se o professor formador diferencia o inglês como língua estrangeira do inglês como língua franca. Constatado isso, a autora investiga qual a relevância, segundo as participantes, do ensino do inglês visto sob a perspectiva de língua franca na formação inicial docente, sua inclusão no currículo do curso e como esta questão reflete na prática de sala de aula e nos materiais didáticos. El Kadri conclui que as professoras formadoras têm avançado, pois corroboram a necessidade de mudança do currículo no curso de Letras e veem a possibilidade de formulação do próprio material didático.

$\mathrm{Na}$ mesma instituição em que El Kadri desenvolveu sua pesquisa tendo como participantes os professores formadores, Adriana Grade Fiori Souza, Carla F. Barcaro e Gabriela Claudino Grande, no oitavo capítulo, têm o objetivo de investigar o que pensam 
os futuros professores, especificamente do quarto ano do curso, sobre o estatuto do inglês como língua franca, bem como demonstrar de que forma as representações das alunasprofessoras estão sendo evidenciadas em seus discursos. Como embasamento teórico, as autoras utilizam-se do conceito de representação de Moscovici e de inglês como língua franca. A partir dos dados coletados, as autoras identificaram cinco categorias nos discursos das participantes: a) nativos e não-nativos, b) a multiplicidade de variedades da língua inglesa, c) inclusão ou exclusão d) inteligibilidade e e) implicações para o ensino.

Clarissa Menezes Jordão, no capítulo nove, discute a língua inglesa como língua internacional e suas implicações para a sala de aula. A autora argumenta que a língua inglesa, em seu estatuto de língua internacional, muda o contexto de sala de aula, sendo este o espaço ideal para a resistência à imposição de maneiras homogeneizantes do saber, produzindo assim, construção de sentidos e formação de subjetividades. Para que este trabalho diferenciado em sala de aula ocorra, a autora propõe a metodologia da OSDE (Open Space for Dialogue and Enquiry), ofertando um conjunto de procedimentos que podem ser adaptados para diferentes grupos de idade e contextos. Tendo suas bases no pósestruturalismo, na pós-modernidade e na teoria da complexidade, o questionamento conceitual se apresenta no contexto educacional como um espaço para diálogos e questionamentos, promovendo, primordialmente, um reposicionamento diante de questões políticas e sociais mais amplas, dentro e fora da sala de aula, segundo a autora.

Em relação ao ensino de língua inglesa em contextos específicos, no décimo capítulo, Cláudia Hilsdorf Rocha e Kleber Aparecido da Silva discutem o ensino/aprendizagem de língua estrangeira nos anos iniciais da Educação Básica dentro de uma perspectiva crítica. Partindo deste pressuposto, os autores veem o WE como um fenômeno linguístico sui generis com a possibilidade de servir como recurso para o ensino de línguas com fins emancipatórios, visto seu caráter "trans (formador) e trans (cultural)".

Completando o repertório de textos publicados no livro, Sávio Siqueira, em entrevista realizada com Margie Berns, traz vários questionamentos referentes às suas publicações mais recentes que tratam do inglês como língua franca. Primeiramente, Margie Berns não concebe a língua franca como uma nova variedade do inglês, mas como um uso da mesma. Direcionando esta questão para a formação de professores, a autora destaca a importância de se preparar professores em pré-serviço para as questões de variedade da língua e suas implicações. Ela ainda afirma que, apesar deste novo conceito de língua trazer incertezas, tanto para o professor formador como para o professor em pré-serviço, caracteriza-se como uma evolução no campo da formação de professores. Esta entrevista 
encerra a obra como uma espécie de retomada de questões diversas trazidas no livro, o que para nós, funciona como uma estratégia de articulação dos artigos publicados.

Esta intrigante obra faz-nos concluir que o conceito de Língua Franca constitui-se de um alto grau de complexidade, pois abrange questões amplas e, ao mesmo tempo, basilares, tais como, para que, para quem e onde ensinamos inglês. Visto sob este aspecto, Inglês como Língua Franca: ensino-aprendizagem e formação de professores apresenta-se como uma grande contribuição para os professores formadores, professores em pré-serviço e linguistas em geral, extrapolando, desta forma, os limites do ambiente acadêmico, já que ela convida a todos a se engajarem nessa valiosa atividade de reflexão e de rompimento com concepções já cristalizadas sobre o ensino-aprendizagem de língua inglesa no meio educacional.

\section{REFERÊNCIAS}

BECKER, M. R. ELF: Inglês como língua franca. Eletras, Curitiba, v. 19, n. 19, p. 1-10, dez. 2009. In Anais do $\mathbf{1}^{\mathbf{0}}$ Simpósio de Reflexões sobre as Metodologias e Práticas de Ensino de Línguas Estrangeiras Mordernas, Curitiba, 2009.

CANAGARAJAH, S. Negotiating the local in english as a língua franca. Annual Review of Applied Linguistics, Cambridge, v. 26, 2006, p. 197-218.

CRYSTAL, D. English as a global language. Cambridge: Cambridge Univesity Press, 1997.

GIMENEZ, T. English in a new world language order. In: MACHADO, L. T; CRISTOVÃO, V. L. L.; FURTOSO, V. (Org.) Aspectos da linguagem: considerações teórico-práticas. Londrina: EDUEL, 2006, p. 59-72.

Antes de Babel: Inglês como Língua Franca Global. In: anais $\mathbf{7}^{\mathbf{0}}$ Encontro de Letras Linguagem e Ensino - ELLE, n. 7, 2009, p. 1-10.

GRADDOL, D. English next. Londong: British Council, 2006.

JORDÃO, C. M. English as a Foreign Language, globalisation and conceptual Questioning. Globalisation, Societies and Education. V. 7, n. 1, 2009, p. 95-107.

KACHRU, B. Standards, Codification, and Sociolinguistics realism: the English language in the outer circle. In: QUIRK R. \& WIDDOWSON, H. (Ed.) English in the World: Teaching and Learning the Language and Literatures. Cambridge: Cambridge University Press, 1985, p. 11-16.

KIRKPATRICK, A. World Englishes: implications for international communication and English language teaching. Cambridge: Cambridge University Press, 2007. 
LEFFA, V. J. Teaching English as a multinational language. In The Linguistic Association of Korea Journal, Seul, v. 10, n. 1, 2002, p. 29-53.

SEIDLHOFER, B. Research perspectives on teaching English as a lingua franca. Annual Review of Applied Linguistics, Cambridge, v. 24, p. 209-239, 2004.

SIQUEIRA, D. S. P. Inglês como língua internacional: por uma pedagogia intercultural crítica. Tese (Doutorado em letras e Linguística) Universidade Federal da Bahia, Salvador, 2008. 